\title{
A ABORDAGEM TEMÁTICA NO ENSINO DE CIÊNCIAS DOS ANOS INICIAIS - UMA ANÁLISE BIBLIOGRÁFICA
}

\author{
THE THEMATIC APPROACH IN EARLY YEARS SCIENCE TEACHING - A BIBLIOGRAPHIC ANALYSIS \\ DIULIANA NADALON PEREIRA ${ }^{1}$ \\ CRISTIANE MUENCHEN ${ }^{2}$
}

\section{RESUMO}

0 estudo teve como objetivo compreender como a Abordagem Temática vem sendo desenvolvida no Ensino de Ciências nos Anos Iniciais do Ensino Fundamental pelas pesquisas do Encontro Nacional de Pesquisa em Educação em Ciências, bem como discutir possibilidades de sua utilização nesse contexto. Para isso, utilizou-se a Análise Textual Discursiva, na qual emergiram duas categorias: i) Perspectivas de Abordagem Temática e ii) Dinâmicas de aula. As perspectivas evidenciadas contribuem para novas compreensões sobre a natureza da ciência, no desenvolvimento da criticidade e na problematização da realidade. A dinâmica mais utilizada é os Três Momentos Pedagógicos. Ademais, identificou-se a necessidade de utilizar dinâmicas que contextualizem os conhecimentos escolares. Portanto, este estudo apresenta caminhos para a utilização da Abordagem Temática nos Anos Iniciais e, sobretudo, demonstra a carência de pesquisas nesse nível de ensino pela área, por isso, ressalta-se a importância de ampliar os estudos sobre essa perspectiva curricular, assim como utilizar propostas balizadas na Abordagem Temática no contexto dos Anos Iniciais visto suas inúmeras contribuições aos processos educativos.

Palavras-chave: Abordagem Temática. Currículo Escolar. Pesquisas.

\section{ABSTRACT}

The study had as objective understand how the Thematic Approach has been developed in Science Teaching in the Early Years of Elementary School by research carried out by the National Meeting of Research in Science Education, as well as to discuss possibilities for its use in this context. For this, a Discursive Textual Analysis was used, in which two categories emerged: i) Thematic Approach Perspectives and ii) Class Dynamics. The perspectives shown contribute to new understandings about the nature of science, in the development of criticality and in the problematization of reality. The most used dynamic was the Three Pedagogical Moments. Furthermore, the need to use the dynamics that contextualize school knowledge was identified. Therefore, this study presents ways for the use of the Thematic Approach in the Early Years and, above all, demonstrates the lack of research at this level of education in the area, therefore, it emphasizes the importance of using proposals based on the Thematic Approach in the context of the Years Initials.

Keywords: Thematic Approach. School Curriculum. Researches.

\section{RESUMEN}

El estudio tenía como objetivo comprender e investigar cómo se ha desarrollado el Enfoque Temático en la Enseñanza de las Ciencias en los Primeros Años de Educación Primaria a través de la investigación realizada por el Encuentro Nacional de Investigaciones en Educación Científica, así como discutir las posibilidades de su uso en este contexto. Para ello se utilizó el Análisis Textual Discursivo, en el que emergieron dos categorías: i) Perspectivas del Enfoque Temático

1 Mestra e Doutoranda em Educação em Ciências pela Universidade Federal de Santa Maria (UFSM). E-mail: diulinadalon@gmail.com. Orcid: https://orcid.org/0000-0002-9895-1562

2 Doutora em Educação Científica e Tecnológica pela Universidade Federal de Santa Catarina (UFSC). Professora da Universidade Federal de Santa Maria (UFSM). E-mail: crismuenchen@yahoo.com.br. Orcid: https://orcid.org/0000-0003-3144-0933 
y ii) Dinámica de Clases. Las perspectivas mostradas contribuyen a nuevas comprensiones sobre la naturaleza de la ciencia, el desarrollo de la criticidad y la problematización de la realidad. La dinámica más utilizada fueron los Tres Momentos Pedagógicos. Además, se identificó la necesidad de utilizar dinámicas que contextualicen el conocimiento escolar. Por lo tanto, este estudio presenta formas para el uso del Enfoque Temático en la Primera Infancia y, sobre todo, demuestra la falta de investigación en este nivel educativo en el área, por lo que enfatiza la importancia de utilizar propuestas basadas en el Enfoque Temático. en el contexto de las iniciales de los años.

Palabras-chave:. Enfoque Temático. Currículum Escolar. Investiga.

\section{INTRODUÇÃO}

Pesquisas na área da Educação em Ciências vêm sugerindo a utilização de propostas baseadas na perspectiva da Abordagem Temática (AT) (CENTA, 2015; HALMENSCHLAGER, 2014; MAGOGA, 2017; MUENCHEN, 2010). Essa pode ser utilizada em diferentes níveis e modalidades de ensino. Delizoicov, Angotti e Pernambuco (2011, p. 189) a definem como uma "[...] perspectiva curricular cuja lógica de organização é estruturada com base em temas, com os quais são selecionados os conteúdos de ensino de disciplinas. Nesta abordagem a conceituação científica da programação é subordinada ao tema". Por essas razões, a adoção da AT desde os Anos Iniciais contrapõe 0 ensino linear, fragmentado e propedêutico predominante nos contextos educativos (AULER, 2007), pois está balizada em um ensino problematizador e dialógico. Ademais, destaca-se que propostas desenvolvidas a partir dessa perspectiva possibilitam a flexibilização curricular e atribui significados aos conhecimentos científicos, visto que partem das situações significativas (DELIZOICOV; ANGOTTI; PERNAMBUCO, 2011). Utilizá-la nos anos iniciais, pode favorecer a apreensão das temáticas, possibilitando o desvelamento da realidade vivida pelas crianças, bem como na superação de suas contradições sociais (SILVA, 2004).

Todavia, em uma pesquisa realizada por Bastos (2013) ao analisar os principais periódicos e eventos da área (ENPEC - Encontro Nacional de Pesquisa em Educação em Ciências; EPEF - Encontro de Pesquisa no Ensino de Física; e, SNEF - Simpósio Nacional de Ensino de Física), constata a incipiência de pesquisas em Ensino de Ciências nos Anos Iniciais que utilizam de referenciais progressistas, como é o caso de Paulo Freire. Assim, os pressupostos freireanos podem estar sendo pouco explorados e compreendidos nesse nível de ensino. Atrelado a isso, Marques (2019) ao realizar um processo formativo com educadoras dos Anos Iniciais identifica que essas profissionais apresentam dificuldades em compreender as contribuições freireanas ligadas ao currículo, ficando limitadas às categorias freireanas, tais como: diálogo, amorosidade, conscientização, dentre outras. Os escritos de Paulo Freire representam um importante referencial para a AT, especialmente, em algumas de suas vertentes, que são estruturadas a partir dos pressupostos do autor.

Além de haver poucas pesquisas que utilizam referenciais freireanos no Ensino de Ciências dos Anos Iniciais, identifica-se a escassez de pesquisas voltadas ao ensino e aprendizagem de ciências nos Anos Iniciais, de maneira geral (CARVALHO; GlL-PÉREZ, 2006). Em corroboração ao exposto Viecheneski e Carletto (2013) sinalizam que as pesquisas em Educação em Ciências, sobretudo, no contexto nos anos iniciais, têm relevado uma preocupação acerca do ensino nesse contexto. Assim, percebe-se que 0 Ensino de Ciências nos primeiros anos ainda tem sido bastante negligenciado (MAESTRELLI, 2018). Em um estudo conduzido por Viecheneski e Carletto (2011) ao analisarem as práticas de Ensino de Ciências por educadores e educadoras dos anos iniciais, evidenciam a necessidade de buscar novas 
abordagens para 0 ensino de Ciências, nesse sentido, as autoras sugerem a utilização da educação Ciência, Tecnologia e Sociedade (CTS), como uma abordagem de destaque na literatura nacional e estrangeira. Tendo-se em vista que a educação CTS é um tipo de AT, corrobora-se para a necessidade de estudos nesse nível, especialmente, relacionados a perspectiva da AT.

Portanto, este artigo pretende: i) compreender como a AT vem sendo desenvolvida nos Anos Iniciais do Ensino Fundamental pelos trabalhos publicados no ENPEC (1997-2019); e, ii) discutir as possibilidades da utilização da AT nesse nível de ensino. Sinaliza-se que a análise foi realizada somente nesse evento em função de sua representatividade - sendo o maior evento da área de Educação em Ciências no Brasil e por envolver todas as edições ocorridas até o presente momento.

\section{ABORDAGEM TEMÁTICA E 0 ENSINO DE CIÊNCIAS NOS ANOS INICIAIS}

0 Ensino de Ciências nos Anos Iniciais, historicamente, apresenta diversos desafios. Longhini (2008) e Silva (2006) sinalizam que a utilização inadequada dos livros didáticos, o foco somente em alguns temas, as abordagens distantes do contexto social das crianças e a desconsideração dos conhecimentos dos educandos e das educandas, são exemplos de lacunas nos primeiros anos de escolarização, por isso, necessitam de um olhar mais atento para que possam ser superadas.

Em contrapartida a esses desafios, salienta-se que o Ensino de Ciências tem como uma de suas funções promover a alfabetização científica e tecnológica, considerando que a ciência e a tecnologia estẫo presentes na realidade de uma parte significativa da população (VIECHENESKI; LORENZETTI; CARLETTO, 2015). Para Lorenzetti e Delizoicov (2001) quando essas discussões são inseridas desde os anos iniciais, podem favorecer o desenvolvimento de uma cultura científica. Além disso, contribui para uma concepção de ciência enquanto produção humana e, sobretudo, que não é neutra, tampouco, salvacionista de todos os problemas da humanidade. Em corroboração, é preciso compreender que os avanços científicos e tecnológicos, podem também trazer prejuízos à população (AULER; DELIZOICOV, 2001). Por isso, o Ensino de Ciências deve ser problematizador desde os anos iniciais e estar em diálogo com a realidade dos estudantes. Bizzo (2009) defende que o Ensino de Ciências seja significativo para os e as estudantes, ultrapassando a simples aprendizagem de terminologias ou de experiências científicas.

Contudo, uma limitação identificada nos cursos de Pedagogia é que a sua formação é bastante ampla em termos de atuação e áreas do saber, ficando difícil de aprofundá-las durante a graduação. Conforme Souza, et al. (2017) a formação caracteriza-se como polivalente, isso é, entre suas competências profissionais está o domínio de múltiplas áreas do conhecimento. A consequência disso, é o pouco domínio dos saberes específicos das áreas. Nesse sentido Longhini (2008) sinaliza que educadores e educadoras dos anos iniciais podem apresentar carências nos conhecimentos que devem ensinar. Essa carência também é evidenciada por Gatti (2010) quando investiga cursos de Pedagogia do Brasil. A autora identifica que somente $7,5 \%$ do currículo dos cursos é destinado para disciplinas das áreas específicas (ciências, história, artes, português, etc.) a serem abordadas durante os anos iniciais. Assim, os conhecimentos abordados durante os Anos Iniciais podem não estar sendo tão aprofundados durante a formação inicial de pedagogos e pedagogas.

Muitas das abordagens utilizadas pelos educadores e pelas educadoras estão balizadas numa concepção bancária de educação, isto é, são desenvolvidas de maneira antidialógica e com a visão acrítica do conhecimento (FREIRE, 2018). No intuito de superar esses problemas educacionais, algumas propostas vêm sendo desenvolvidas e sugeridas, a exemplo da AT (ALMEIDA; GEHLEN, 2019; 
KLEIN; MUENCHEN, 2020). A AT se caracteriza como uma perspectiva de reestruturação curricular pautada em temas. Nessa abordagem, os temas são selecionados ou emergidos a fim de gerar significado ao que se é ensinado. Os conceitos científicos, nessa perspectiva, auxiliam na apreensão dos temas (DELIZOICOV; ANGOTTI; PERNAMBUCO, 2011). Além disso, essa concepção curricular está pautada nos princípios da dialogicidade e da problematização (MAGOGA; MUENCHEN, 2020).

Ao longo do tempo, considerando os objetivos e as finalidades das propostas desenvolvidas através da AT, percebeu-se a existência de algumas vertentes, dentre essas: a Abordagem Temática Freireana (ATF), a educação CTS, a perspectiva Freire - CTS, dentre outras. As principais diferenças entre essas vertentes dizem respeito a obtenção e natureza do tema utilizado.

Na ATF o tema é obtido a partir de investigações na comunidade e no contexto escolar - de onde emergirá um Tema Gerador (TG) que representa uma contradição social ou situação-limite. Nesses casos, existem diferentes metodologias de obtenção de temas, como por exemplo, em 5 etapas do processo de Investigação Temática (IT) (DELIZOICOV; ANGOTTI; PERNAMBUCO, 2011), em 4 etapas do processo de IT (FREIRE, 2018), pelos 3 Momentos Pedagógicos (3MP) (MUENCHEN, 2010) ou através da Práxis Curricular Via TG (SILVA, 2004). Já no caso da educação CTS, o tema pode selecionado com base nas necessidades percebidas pelo educador ou pela educadora. Todavia, nessa vertente 0 tema deve possuir algumas características básicas, as quais são: i) apresentar-se como controverso; ii) apresentar significado social; e, iii) apresentar alguma dimensão relativa à ciência e à tecnologia (RAMSEY, 1993). Por fim, a educação Freire - CTS, apresenta elementos de ambas as dimensões, isso é, está balizada na perspectiva educacional freireana, onde se busca um TG, o qual contemplará a dimensão da Ciência, da Tecnologia e da Sociedade. A educação CTS e a perspectiva freireana possuem diversas convergências, dentre elas, a própria AT, ou seja, ambas utilizam temas, os quais buscam a superação das contradições sociais (ALMEIDA; GEHLEN, 2019). Isto posto, a articulação entre esses referenciais propicia a superação da cultura do silêncio e do modelo de decisão tecnocrática (AULER; FENALTI; DALMOLIN, 2009).

Nesse sentido, a adoção da perspectiva AT é uma possibilidade que tem muito a contribuir para os processos de ensino e aprendizagem, bem como no desenvolvimento de uma educação libertadora. Portanto, na sequência serão apresentados os caminhos metodológicos para compreender a utilização da AT no Ensino de Ciências dos Anos Iniciais e suas possibilidades educativas.

\section{CAMINHOS METODOLÓGICOS}

Este estudo caracteriza-se como qualitativo e de cunho bibliográfico, em que foi realizada uma análise dos trabalhos publicados nas 12 edições do ENPEC, que discutiam a AT no Ensino Fundamental - Anos Iniciais.

A justificativa da seleção deste evento para realizar a análise é devido a este "concentrar, socializar e divulgar as pesquisas em educação em Ciências em áreas específicas como a Biologia, Química e Física. Além disso, a maioria dos trabalhos apresentados no ENPEC reflete a produção dos programas de pós-graduação [...]" (MUENCHEN, 2010, p. 22). Além disso, o evento conta com a participação ativa de diversos pesquisadores e pesquisadoras em AT, incluindo, os líderes de grupos de pesquisa sobre 0 assunto. Nesse sentido, 0 evento vem sendo amplamente utilizado como divulgador e lócus de investigação da AT, a exemplo dos estudos desenvolvidos por (KLEIN; MUENCHEN, 2020; MAGOGA; SILVA; MUENCHEN, 2020; NERES; GEHLEN, 2018) em que os autores também utilizaram 0 evento para realização de pesquisas sobre AT 
Acerca dos caminhos metodológicos adotados, inicialmente, foram realizadas buscas no site do ENPEC, utilizando os termos "Abordagem Temática", "Ensino Fundamental", "Anos iniciais", "Primeiros anos" e "Séries iniciais". Posteriormente, realizou-se a leitura dos títulos, resumos e metodologias de todos os trabalhos previamente selecionados. A leitura visava identificar quais dos trabalhos realmente foram desenvolvidos nos Anos iniciais. Desse modo, verificou-se que muitos deles haviam apenas rápidas citações, as quais não eram foco e, portanto, foram retirados da análise. 0 quadro 1 apresenta a relação do número de trabalhos publicados em cada edição do ENPEC, bem como o total de trabalhos sobre a AT no âmbito do Ensino Fundamental - Anos iniciais.

Quadro 1 - Relação dos trabalhos do ENPEC sobre AT e Anos Iniciais.

\begin{tabular}{|c|c|c|c|c|c|}
\hline Ano & $\begin{array}{c}\mathbf{N}^{\mathbf{0}} \text { da } \\
\text { edição }\end{array}$ & $\begin{array}{c}\mathbf{N}^{\mathbf{0}} \text { de } \\
\text { trabalhos }\end{array}$ & $\begin{array}{c}\mathbf{N}^{\mathbf{0}} \text { de trabalhos com o termo } \\
\text { Abordagem Temática }\end{array}$ & $\begin{array}{c}\text { Com o termo Ensino } \\
\text { Fundamental e AT }\end{array}$ & $\begin{array}{c}\text { Sobre AT e } \\
\text { Anos Iniciais }\end{array}$ \\
\hline 1997 & 1 & 57 & 0 & 0 & 0 \\
\hline 1999 & 2 & 163 & 1 & 0 & 0 \\
\hline 2001 & 3 & 233 & 0 & 1 & 0 \\
\hline 2003 & 4 & 451 & 5 & 3 & 1 \\
\hline 2005 & 5 & 739 & 9 & 8 & 0 \\
\hline 2007 & 6 & 669 & 16 & 7 & 0 \\
\hline 2009 & 7 & 799 & 13 & 15 & 0 \\
\hline 2011 & 8 & 1235 & 29 & 14 & 1 \\
\hline 2013 & 9 & 1036 & 31 & 13 & 3 \\
\hline 2015 & 10 & 1116 & 31 & 14 & 2 \\
\hline 2017 & 11 & 1343 & 31 & 13 & 8 \\
\hline 2019 & 12 & 1251 & 25 & 88 & 0 \\
\hline Total & 11 & 9092 & 191 & & 0 \\
\hline
\end{tabular}

Fonte: Elaborado pelas autoras.

Quadro 2 - Relação de trabalhos selecionados sobre AT nos Anos Iniciais.

\begin{tabular}{|c|c|l|}
\hline Código & Ano & \multicolumn{1}{c|}{ Título } \\
\hline T1 & 2003 & Formando pedagogos para ensinar ciências nas séries iniciais do ensino fundamental \\
\hline T2 & 2013 & A contextualização na Abordagem Temática Freireana e no Ensino de Ciências por Investigação. \\
\hline T3 & 2015 & O processo de Redução Temática do Tema Gerador "Para onde vai o lixo do meio rural de Iguaí/BA?". \\
\hline T4 & 2017 & Do que a Ciência se ocupa? Uma etapa na pesquisa sobre enfoque CTS no ensino fundamental. \\
\hline T5 & 2017 & Ciências nos Anos Iniciais: que ensino é esse? \\
\hline T6 & 2017 & Atividades experimentais - a ampliação na leitura de mundo dos alunos nos anos iniciais. \\
\hline T7 & 2019 & $\begin{array}{l}\text { Formação docente a partir de uma adaptação dos Três Momentos Pedagógicos: experiência em uma escola de } \\
\text { Santa Maria - RS. }\end{array}$ \\
\hline T8 & 2019 & Corpo humano ou ser humano? Um guia didático para o Museu de Ciências da Vida com foco nos anos iniciais. \\
\hline
\end{tabular}

Fonte: Elaborado pelas autoras. 
Após isso, os trabalhos foram analisados, seguindo a metodologia da Análise Textual Discursiva, que se organiza em três etapas: unitarização, categorização e produção de metatextos (MORAES; GALIAZZI, 2011).

Na unitarização foi realizada a desmontagem dos textos, isso é, foram retirados fragmentos denominados unidades de significado. As unidades foram identificadas com códigos dos trabalhos (ex:T1, T2, T3...) e foram acrescidos códigos alfanuméricos referentes a ordem crescente das unidades (ex:U1, U2, U3...), formando um código composto por dois elementos (ex: T1_U1, T1_U2, T2_ U1...). Na segunda etapa - categorização ocorreu o estabelecimento de relações entre as unidades, a partir de aproximações entre elas, dando origem às categorias de análise. Na última etapa - produção de metatextos - foi produzido um novo significado, por meio da construção dos metatextos, os quais possibilitam uma compreensão renovada do todo (MORAES; GALIAZZI, 2011).

Durante a categorização, emergiram as seguintes categorias: 1) Perspectivas de AT e 2) Dinâmicas de aula. As mesmas são discutidas com o intuito de sinalizar um possível panorama de como a AT vem sendo desenvolvida no Ensino de Ciências dos Anos Iniciais, bem como elucidar algumas lacunas e/ou possibilidades a serem trabalhadas.

\section{RESULTADOS E DISCUSSÃO}

\section{PERSPECTIVAS DE AT}

A partir da análise observou-se a presença de duas perspectivas de AT nas pesquisas, sendo elas: 1) CTS e 2) ATF. Além disso, o trabalho T8 apresenta uma proposta de formação continuada organizada a partir de uma AT, mas não se intitula e nem apresenta elementos que tornam possível enquadrá-la dentro das perspectivas mencionadas (CTS e ATF). 0 uso da AT, neste caso, pretendia contribuir para alfabetização científica das educadoras dos anos iniciais, por meio da validação de um guia didático sobre a temática, conforme a unidade T8_U1 abaixo:

A proposta educativa foi estruturada por abordagem temática, segundo o modelo metodológico dos três momentos pedagógicos (problematização, organização do conhecimento e aplicação do conhecimento) [...]visando contribuir para promoção da alfabetização científica dos professores de Ciências dos anos iniciais do ensino fundamental (T8_U1).

A perspectiva CTS foi utilizada pelos trabalhos T1 e T4. Na análise dos resultados, observou-se que esta pode contribuir, principalmente, para: i) desenvolver uma concepção crítica da ciência; ii) gerar maior contextualização entre os conhecimentos e disciplinas; e, iii) favorecer uma maior participação dos educandos e das educandas.

No entanto, vale salientar que o trabalho $\mathrm{T} 1$ desenvolve uma proposta que, segundo as autoras, se enquadra em uma AT articulada a educação CTS, o qual se baseia na elaboração de um Projeto Temático, conforme pode ser visualizado na unidade T1_U1:

Os projetos deveriam ter [...] o planejamento e organização do ensino de ciências a partir de uma abordagem temática [...]Mas, também, deveriam ser planejados a partir das perspectivas: (a) Ciência, Tecnologia e Sociedade e 0 ensino de ciências [...] (T1_U1). 
As autoras do trabalho T1_U1 salientam que os projetos seriam organizados a partir de uma perspectiva de AT. Contudo, é acrescido que também deveriam utilizar a educação CTS nos projetos. Possivelmente, interpretam a AT e a educação CTS como elementos distintos, não considerando a educação CTS como um tipo de AT, visto que, segundo elas, os estudantes deveriam utilizar tanto a AT quanto a educação CTS. Com isso, sinaliza-se que pode estar havendo uma apropriação equivocada da AT e uma incompreensão sobre suas perspectivas.

Foram destacadas anteriormente algumas contribuições evidenciadas durante a análise dos trabalhos, a partir da implementação dessas perspectivas, sendo assim uma delas era a de "desenvolver uma concepção crítica da ciência”. Essa contribuição pode ser visualizada nas unidades T4_U3 e T4_U5.

Logo, o movimento CTS surgiu em contraposição ao modelo desenvolvimentista que se sustentava na supervalorização da ciência (cientificismo) e na sua neutralidade (T4_U3).

As reflexões apontadas sobre a relação entre ciência e questões sociais levam-nos a identificar as atividades em que elas ocorreram como momentos de ensino de Ciências que permitiram uma leitura mais crítica do mundo, contribuindo para uma visão mais dinâmica e humana de ciência - como aquela que sofre interferências e interfere na sociedade (T4_U5).

Conforme as unidades acima há uma aparente compreensão da ciência como neutra, isto é, isenta de interesses próprios. Esse entendimento se distancia da visão de que a ciência interfere nas questões sociais. Por isso, a educação CTS visa a superação da concepção da neutralidade da ciência, do modelo de decisões tecnocráticas e da perspectiva salvacionista, geralmente, atribuída à Ciência e à Tecnologia (AULER, 2007). Em consonância, a unidade T4_U5 aborda que a leitura crítica do mundo possibilita uma compreensão renovada da ciência, como um processo dinâmico e de interferências sociais (AULER, 2007). Isso pode ser um indicativo da importância de problematizar a realidade, para que os educandos e as educandas realizem a sua própria leitura crítica de mundo, a qual pode ser favorecida através de propostas pautadas na educação CTS.

Em relação a contribuição de "gerar maior contextualização entre os conhecimentos e disciplinas", foi contemplada por algumas unidades, dentre elas a T4_U1, T4_U4 e a T4_U18, conforme podem ser vistas abaixo:

Discutir e compreender as relações CTS permite minimizar a fragmentação dos conhecimentos, que [...] é uma necessidade, sobretudo nos anos iniciais do ensino básico - Ensino Fundamental I (EFI) (T4_U1).

São apontadas ainda como características do ensino CTS a abordagem interdisciplinar, que reúne áreas do conhecimento pertencentes às ciências naturais e sociais; [...] (T4_U4).

É sugestiva a proposta de trabalhar as relações CTS a partir de saúde e meio ambiente, temas considerados como transversais pelos Parâmetros Curriculares Nacionais [...] A condição transversal desses temas possibilita 0 diálogo entre várias disciplinas (T4_U18). 
A abordagem de temas CTS através de planejamentos interdisciplinares vem sendo discutida por diversos autores (AULER, 2007; SANTOS MORTIMER, 2002). A principal defesa adotada por eles, no que tange a utilização da interdisciplinaridade, se justifica pelos temas apresentarem grande complexidade, o que dificulta compreendê-los por meio de abordagens pautadas em uma perspectiva unicamente disciplinar. Nesse sentido, o envolvimento de outras disciplinas possibilita uma visão mais ampla do tema e, portanto, da própria realidade.

Acerca da contribuição de "favorecer uma maior participação dos educandos", essa foi identificada nas unidades T4_U11 e T4_U13, as quais encontram-se abaixo:

Os comentários mostram a intenção de desenvolver um trabalho pedagógico por meio de uma temática socialmente relevante, que buscasse a valorização da atuação do aluno como cidadão [...] (T4_U11).

[...] podendo contribuir para uma exploração mais profícua das relações CTS nos anos iniciais do ensino fundamental e para a formação crítica do cidadão (T4_U13).

Em ambas as unidades são exploradas o potencial dos temas CTS de gerar maior autonomia nos educandos e nas educandas e 0 desenvolvimento da cidadania. Em corroboração, Aikenhead (1987) e Auler (2007) sinalizam que a educação CTS pode promover maior interesse dos estudantes para estabelecer relações entre a ciência, a tecnologia e os aspectos sociais inferentes. Além disso, os temas CTS podem contribuir para a aquisição de compreensões sobre a natureza da ciência e na formação de sujeitos alfabetizados cientifico-tecnologicamente. Muenchen (2006) salienta que ao se inserir temas CTS no contexto escolar, se considera o educando e a educanda como um ser social e 0 conhecimento científico como elemento essencial no desenvolvimento da cidadania.

A partir dos critérios adotados nesta pesquisa, constatou-se que quatro trabalhos (T2, T3, T6, T7) utilizavam ou discutiam a ATF. Evidenciou-se que todos esses possuíam uma natureza mais prática, isto é, foram desenvolvidos processos educativos no Ensino Fundamental - Anos Iniciais (com educadores/educadoras ou diretamente com os educandos/educandas). A observação realizada indica que há uma predominância no ENPEC, no escopo analisado, de trabalhos práticos que utilizam a ATF. Além disso, a maioria (T2, T3, T7) foi desenvolvida no $5^{\circ}$ ano do Ensino Fundamental, sendo 0 trabalho T7 com educadores e educadoras deste ano, e, somente o trabalho T6 implementou com estudantes de outro ano do Ensino Fundamental ( $3^{\circ}$ ano do fundamental). Assim, é possível reconhecer que as propostas, nesse caso, se concentram, especialmente, no último ano do Ensino Fundamental - Anos Iniciais, por isso, torna-se importante que pesquisas baseadas na AT sejam implementadas desde os primeiros anos do Ensino Fundamental. Contudo, necessitaria um estudo mais aprofundado para identificar se isso é uma ocorrência frequente em nível nacional ou se foi uma evidência restrita dos estudos publicados no ENPEC. Além disso, poderiam ser investigadas as razões dessa ocorrência ser maior nos últimos anos, em caso de confirmação da hipótese.

Como resultado da análise das pesquisas, percebeu-se que a perspectiva ATF vem sendo desenvolvida, especialmente, a fim de: i) gerar a problematização e compreensão da realidade; ii) superar as situações-limites 3 ; e, iii) reorganizar 0 currículo.

3 Situações-limites são obstáculos que, muitas vezes, encontram-se naturalizados pelos sujeitos, ou seja, não conseguem identificá-los em sua realidade, por isso, necessitam tomar consciência de sua existência. Quando os sujeitos confrontam essas situações-limites estão exercendo sua vocação ontológica de "ser mais" (FREIRE, 2018). Conforme Gadotti (1996, p. 730) esses obstáculos "não devem ser contornadas, mas analisadas, enfrentadas e estudadas em suas múltiplas contradições, sob pena de reaparecerem mais adiante com força redobrada". 
Em relação a finalidade de "gerar a problematização e compreensão da realidade", existem duas discussões centrais, uma delas relacionada a problematização da realidade - que exige dialogicidade e criticidade, e a outra, na aprendizagem de novos conhecimentos - conceitos científicos - que auxiliam na compreensão da realidade (DELIZOICO; ANGOTTI; PERNAMBUCO, 2011).

Um planejamento pautado nos pressupostos freireanos não se restringe a abordagem do conteúdo programático, mas da relação que este conteúdo tem com os problemas relacionados à realidade dos alunos (T3_U11).

A atividade relatada nesta pesquisa evidencia o quanto é importante abrir espaço nas aulas para que os estudantes possam exprimir a sua leitura de mundo sobre um determinado tema [...] (T6_U2).

Já acerca da finalidade e contribuição de favorecer uma maior e melhor compreensão da realidade, as unidades T2_U5 e T2_U3 apresentam um pouco desta discussão, conforme pode ser visto abaixo:

Embora a Abordagem Temática Freireana e $0 \mathrm{ENCl}^{4}$ apontam para a importância da articulação entre 0 contexto dos alunos e 0 ensino dos conceitos científicos, há indicativos de que ambas apresentam particularidades quanto ao enfoque dado à contextualização (T2_U5).

Já a problematização na Abordagem Temática Freireana consiste em fazer com que os estudantes se afastem de forma reflexiva dos seus conhecimentos vulgares, a fim de que sintam necessidade de adquirir novos saberes (T2_U3).

Por isso, considera-se que os conceitos científicos são de extrema relevância para a compreensão do tema, no entanto, devem estar sempre subordinados a ele, isto é, o tema ocupa posição central na ATF (DELIZOICOV; ANGOTTI; PERNAMBUCO, 2011).

A finalidade de "superação das situações-limites", encontra-se presente nas unidades T3_U9, T3_U10 e T6_U4, conforme podem ser visualizadas abaixo:

Sendo a Redução Temática ${ }^{5}$ essencial para a promoção de um Ensino de Ciências que estimule a leitura do mundo e compreensão e superações de situações-limite por meio de conceitos científicos (T3_U9).

Nesse contexto, sinaliza-se para a relevância da articulação dos conteúdos abordados com a compreensão da comunidade escolar sobre o tema gerador, tendo em vista a superação e compreensão ampla dos problemas inerentes à sua realidade (T3_U10).

A utilização de temas do cotidiano dos estudantes na condução do processo de ensino aprendizagem possibilita que estes exprimam e ampliem a sua leitura de mundo, contribuindo ainda para que se tornem mais ativos nas tomadas de decisões no seu dia-a-dia [...] (T6_U4).

5 A Redução Temática é uma das etapas da IT propostas por Freire (2018) e, posteriormente, sistematizadas por Delizoicov (1982). Nessa etapa, são selecionados os conhecimentos científicos para a construção curricular, esses têm a finalidade de favorecer a compreensão do tema (NOVAIS, et al., 2015). 
Ao se ter o tema como objeto de problematização e compreensão da realidade, provoca-se no educando e na educanda o desenvolvimento da conscientização da realidade em que estão inseridos. Isso, por sua vez, é essencial para que haja a superação dos problemas e das situações contraditórias. Desse modo, é preciso que o tema seja legítimo e represente o mundo-vida do educando/educanda, assim, processos de investigação da realidade como estruturante de currículo (HALMENSCHLAGER, 2014) são de extrema importância. A ATF enquanto estruturante curricular, também é discutida dentro dos trabalhados analisados, estando presentes nas unidades abaixo:

Nesse sentido, a etapa da Redução Temática não pode ser vista como uma simples tarefa de selecionar conteúdos/conceitos para compreender o tema/problema. Entende-se como uma atividade complexa composta por diferentes fases que se complementam, a qual integra um processo mais amplo de reestruturação curricular, neste caso, a Investigação Temática (T3_U7).

[...] 0 desenvolvimento [...] temas [...] implica em novas compreensões sobre 0 currículo por parte dos docentes e da equipe diretiva, os quais devem considerar 0 currículo como espaço de construção coletiva [...] e ao mesmo tempo esteja em consonância com o contexto do educando (T5_U3).

A unidade T3_U7 discute que, a reestruturação curricular via ATF, não é um processo simples baseado na mera seleção de conteúdos- sobretudo, perpassa diversas etapas e implica olhar para realidade, com base em suas contradições. A reestruturação de currículos ocorre a partir da identificação de temas de maior relevância social, os TG, os quais se caracterizam como situações-limites vivenciadas pelos sujeitos (AULER; DALMOLIN; FENALTI, 2009). Para que os temas tenham legitimidade, é preciso desenvolver um processo de IT, que pode ocorrer de diferentes maneiras, como sinalizado anteriormente no referencial teórico. A ATF defende a reinvenção dos currículos tradicionais, pautados na educação bancária, para a construção de currículos pensados coletivamente (T5_U3). Por isso, destaca-se a importância de currículos comprometidos eticamente com a liberdade, com 0 diálogo, com a problematização e com a democracia (SILVA; GOMES, 2019).

Portanto, a AT - enquanto estruturante curricular- transcende a simples reprodução de práticas e metodologias de ensino. Essa proposta auxilia na busca por novos caminhos possíveis, os quais visam construir uma educação de qualidade e fundamentada na solidariedade (MAGOGA; MUENCHEN 2020).

\section{DINÂMICAS DE AULA}

Da análise dos trabalhos emergiram discussões acerca das dinâmicas de aula realizadas a partir da AT. Assim, evidenciaram-se alguns elementos que norteavam essas discussões. Os mesmos referenciam-se, principalmente, a: 1) metodologias de ensino; 2) recursos didáticos; 3) condução das discussões; e, 4) avaliação da aprendizagem.

Em relação ao primeiro item que trata sobre as "metodologias de ensino utilizadas", evidenciou-se: Ensino por Investigação (T2), Ensino através da Experimentação (T6, T7), e os 3 MP (T2, T3, T6, T7, T8). A exemplo o trabalho $\mathrm{T} 7$ realizou um processo formativo com educadoras dos anos iniciais, no qual utilizou os 3MP como norteadores das atividades, contudo, a partir do Estudo da Realidade (uma das etapas dos 3 MP, usaram a dinâmica do Ensino por Experimentação. Assim, sinaliza-se que os 
3 MP vêm sendo utilizados tanto como metodologia de ensino em sala de aula, como organizadores de processos formativos, tal como sugere Muenchen (2010). As unidades T7_U1 e T7_U2 consideram que 0 uso dos 3 MP pode ser readaptado, conforme a pertinência e necessidade.

Nesse contexto, visando à realização de um processo de formação com professores de séries iniciais em uma escola de Santa Maria, buscamos uma adaptação da dinâmica dos 3MP, bem como a partir da problematização e do diálogo tentou-se um exercício de ER (T7_U1).

Com relação ao apresentado neste trabalho, considera-se que todo o processo fez parte de uma releitura da bibliografia estudada e ainda, da adaptação do que vem sendo construído a respeito dos 3MP, como já mencionado no referencial (T7_U2).

Salienta-se que a predominância da dinâmica dos 3MP nessas propostas, pode ser justificada, pois a última etapa - trabalho em sala de aula- pertencente as 5 etapas do processo de IT de Delizoicov (1991), foi desenvolvida a partir dos 3 MP. Por isso, a sua utilização tanto como dinâmica de aula (DELIZOICOV; ANGOTTI; PERNANBUCO, 2011) ou enquanto estruturante de currículos (MUENCHEN, 2010) pode contribuir para a superação da educação bancária (FREIRE, 2018), notadamente, por considerar como central a ação dialógica-problematizadora dos processos educativos. Além disso, outras contribuições podem ser oriundas da utilização dos 3MP, tais como a realização de uma leitura de mundo e uma maior motivação dos educandos e educandas.

Como tentativa de aproximar áreas disciplinares buscou-se desenvolver uma sequência didática baseada nos TMP, relacionando conhecimentos de diferentes campos das Ciências Naturais e possibilitando aos estudantes que expressassem a sua leitura de mundo sobre o tema abordado: Alimentação (T6_U3).

A utilização dos Três Momentos Pedagógicos contribuiu efetivamente para que os estudantes se sentissem motivados na abordagem e discussão do tema, uma vez que os conhecimentos trazidos por eles não se mostraram suficientes para a resolução dos problemas apresentados (Problematização Inicial) (T6_U5).

Tal como expressa nas unidades acima, a articulação dos 3MP na implementação de propostas balizadas pela AT, pode estar propiciando um trabalho mais significativo e muito disso ocorre em função de sua natureza dialógica e problematizadora (ARAÚJO; NIEMEYER; MUENCHEN, 2013). Através disso, pode-se despertar maior interesse dos educandos e das educandas pelo conhecimento, bem como pode contribuir para a superação da curiosidade ingênua, desenvolvendo assim, a curiosidade epistemológica. Conforme Freire (2003) a curiosidade epistemológica permite ao educando e a educanda saírem do mero senso comum para a produção de novos conhecimentos, os quais apresentam caráter cientifico e crítico. Assim, ressalta-se a importância de estimular nos contextos educativos 0 desenvolvimento e o exercício da curiosidade epistemológica (MAIA; MION, 2008). Salienta-se que as presentes identificações são obtidas a partir das análises - em consonância aos referenciais da área, no entanto, merecem um olhar mais profundo para melhor validar as sinalizações realizadas.

Em relação aos "recursos didáticos utilizados" durante a implementação das propostas e nas discussões dos trabalhos, foram identificados os seguintes: questionário (T1, T2), artigos (T1), 
relatórios (T2), histórias em quadrinhos (T3), músicas (T4), livros/guias didáticos (T4, T5, T8), textos (T5), jogos (T5), materiais para experimentação (T6, T7), confecção de material didático (pirâmide alimentar), livros de receitas e alimentos para degustação (T6). Assim, salienta-se que há uma diversidade de recursos que vêm sendo usados, algo importante para facilitar os processos de ensino e aprendizagem.

Em relação a "condução das discussões", observou-se que essas devem ter como base a contextualização e a problematização, a fim de desenvolver nos sujeitos um pensamento crítico sobre a sua própria realidade, reconhecendo as contradições em que se encontram, conforme consta nas unidades abaixo:

O sentido da problematização é conduzir os alunos à percepção e ao engajamento de que é possível compreender e superar as contradições sociais vividas por eles, que no caso da atividade do "Problema da Pressão" ajudou-os a entenderem melhor os aspectos que envolvem a distribuição da água até as suas casas (T2_U1).

Os relatos indicaram assim, a preocupação com a contextualização do ensino para o estudo e compreensão de um problema socioambiental - a proliferação de um determinado mosquito transmissor de doenças, e suas implicações- no qual os alunos estavam mergulhados. A contextualização, no entanto, não foi vista como uma simples estratégia para motivar o estudo de conteúdos conceituais restritos aos vetores, ciclos de vida dos mosquitos e às doenças transmitidas por eles (T4_U9).

Em relação as "avaliações", nenhum trabalho explorou profundamente as estratégias avaliativas. Alguns relatam a necessidade de avaliar a mudança da compreensão e pensamentos dos estudantes, como pode ser visto na unidade a seguir:

Portanto, existe uma função crítica para o professor-formador - é ele que discernirá os instrumentos de coleta de dados para avaliar a evolução das ideias, opiniões e atitudes de seus alunos (T1_U4).

No entanto, um trabalho (T8) explicitou a forma com que seria realizada a avaliação, como apresentado pela unidade abaixo:

A avaliação ocorreu de forma contínua durante todo o desenvolvimento da formação em serviço, por meio dos seguintes aspectos: 1. Participação e envolvimento nas atividades propostas. 2. Debates. 3. Propostas de intervenção pedagógica (T8_U2).

As avaliações ainda são incipientes nesses trabalhos, pois não são realizadas muitas discussões acerca dos processos avaliativos adotados na implementação das propostas. Essa carência também é evidenciada em outros estudos (PEREIRA; KLEIN; MUENCHEN, 2021, no prelo; KLEIN; PEREIRA; MUENCHEN, 2021), os quais identificam que pesquisas sobre AT não têm explorado devidamente as questões avaliativas. Saul (2015) reflete acerca da avaliação, na qual sinaliza que as avaliações vêm sendo utilizadas com o intuito de controlar o comportamento dos e das estudantes, além disso, buscam verificar a aprendizagem - em relação a expressão do domínio de habilidades e conteúdos. Todavia, Valadares e Graça (1998) salientam a necessidade de compreender a avaliação como orientadora dos processos de ensino e de aprendizagem. Portanto, considera-se a importância 
de se pensar avaliações que estejam coerentes a proposta da AT, nesse sentido, sugere-se a avaliação emancipatória (SAUL, 2008; 2015), a qual apresenta caráter dialógico, problematizador e crítico.

\section{CONSIDERAÇÕES FINAIS}

0 corpus de análise - representado por apenas oito pesquisas- indica a carência de estudos da área no Ensino Fundamental - Anos Iniciais. Em contrapartida, estudos voltados aos Anos Finais do Ensino de Fundamental e Ensino Médio são maioria. Magoga, Centa, Schneider e Muenchen (2014) investigam a frequência de trabalhos publicados no ENPEC (1997-2013) que implementaram atividades no contexto de sala de aula e a sua distribuição por nível de ensino. Dessa pesquisa, resultam 48\% trabalhos implementados no Ensino Médio, 29\% no Ensino Superior, 3\% não identificados e apenas 20\% no Ensino Fundamental (Anos Iniciais e Finais). Contudo, atenta-se que esses 20\% já são minoria e ainda incluem os Anos Finais do Fundamental. As diferenças significativas observadas levam a questionar os motivos pelos quais existe uma maior concentração de estudos nos Anos Finais e Médio em comparação aos Anos Iniciais.

Algumas possíveis explicações são decorrentes da pouca ênfase dada ao Ensino de Ciências nos Anos Iniciais do Ensino Fundamental. Mizukami et al. (2002) discute que durante os Anos Iniciais há uma abordagem majoritária do ensino de matemática e da alfabetização, como consequência disso, disciplinas como a de ciências é pouco abordada. 0 negligenciamento com a área de ciências nos primeiros anos é reflexo de diversas situações, dentre elas o despreparo de educadoras e educadores para essa área, como consequência de uma formação inicial que não dá conta de contemplar adequadamente o Ensino de Ciências. Autores discutem que nos currículos do curso de Pedagogia, além de haver pouca carga horária para disciplinas das áreas específicas (ciências, matemática, português, história, etc.), há uma predominância de aspectos teóricos e poucas possibilidades práticas educativas relacionadas (GATTI; BARRET0, 2009; GATTI, 2010; LIBÂNE0, 2010). Então, intervenções diferenciadas, como é o caso da AT, podem estar sendo pouco utilizadas pelos motivos apresentados.

Tal como anunciado na introdução desta pesquisa, existem algumas lacunas relacionadas ao Ensino de Ciências nos primeiros anos de escolarização, as quais podem ser consequentes dos resultados aqui identificados. Além disso, há baixa incidência de trabalhos com AT nos anos iniciais pode ser oriunda do fato de que o ENPEC é um evento direcionado, principalmente, aos pesquisadores e pesquisadoras da área de Educação em Ciências, cujas formações iniciais, geralmente, são química, física e biologia. Esses profissionais são aptos para atuar nos Anos Finais do Ensino Fundamental e/ou Ensino Médio, assim o olhar desses sujeitos pode estar mais direcionado a esses níveis de ensino por ser o seu local de atuação.

Os resultados desta pesquisa, apontam como possibilidade a articulação da AT como outras abordagens e/ou metodologias de ensino, demonstrando o dinamismo da perspectiva. As propostas metodológicas utilizadas durante as intervenções, demonstraram-se como importantes para despertar 0 interesse dos educandos e das educandas pelo tema, para facilitar a compreensão dos conhecimentos escolares. Outrossim, essas metodologias podem facilitar as contextualizações e problematizações em sala de aula.

Foram também percebidas limitações na utilização da AT, estando algumas associadas as concepções de currículo e a utilização de estratégias avaliativas. Desse modo, a pesquisa aqui realizada serve como indicativo da necessidade de que as concepções de currículo e as avaliações sejam mais 
contempladas e refletidas pelas pesquisas da área que utilizam AT, a fim de que sejam superadas as limitações relacionadas a elas.

Embora os trabalhos estejam voltados aos iniciais, quase não foram observadas discussões acerca desse nível de escolarização pelos trabalhos, dificultando compreender quais são as principais diferenças na aprendizagem, nos interesses e na motivação dos educandos e educandas, em comparação aos de outros níveis ou modalidades de ensino. Por isso, deve haver um olhar para os Anos Iniciais, considerando suas especificidades, havendo a necessidade de maiores e mais profundas discussões acerca desse contexto, pois as sinalizações aqui realizadas foram provenientes de um número pequeno de trabalhos analisados. Em vista disso, seria importante olhar para outros eventos e periódicos, no intuito de ampliar o olhar sobre as possibilidades da utilização da AT nos anos iniciais, assim como aprofundar a compreensão sobre a mesma.

Para finalizar, explicita-se que o estudo feito favoreceu: compreender como a AT vem sendo desenvolvida no Ensino de Ciências dos anos iniciais pelos trabalhos publicados no ENPEC; identificar a carência de estudos sobre 0 assunto nos anos iniciais; apresentar algumas possibilidades de utilização da AT; e demonstrar limitações associadas as avaliações e ao currículo escolar. Por tudo isso, são sinalizações importantes que anunciam a necessidade de aprofundamento a partir da realização de novos estudos, os quais podem ocorrer a partir dos caminhos aqui tecidos.

\section{REFERÊNCIAS}

AIKENHEAD, G. High-school graduates beliefs about science-technology-society: Thecharacteristics and limitations of scientific knowledge. Science Education, v. 71, n. 4, p. 459-487, 1987. DOI: https://doi.org/10.1002/sce.3730710402

ALMEIDA, E. S.; GEHLEN, S. T. Organização curricular na perspectiva Freire-CTS: propósitos e possibilidades para a Educação em Ciências. Ensaio, Belo Horizonte, 2019.

ARAÚJO, L. B.; NIEMEYER, J.; MUENCHEN, C. Uma análise dos trabalhos presentes nos Encontros de Pesquisa em Ensino de Física (EPEF): problematizações ou perguntas? Enzeñanza de las Ciencias, v. 1, p. 188-193, 2013.

AULER, D.; DALMOLIN, A. M. T.; FENALTI, V. Abordagem Temática: natureza dos temas em Freire e no Enfoque CTS. Alexandria, v. 2, n. 1, p. 67-84, 2009.

AULER, D. Enfoque Ciência-Tecnologia-Sociedade: pressupostos para o contexto brasileiro. Ciência \& Ensino, 1 (especial), 2007.

AULER, D.; DELIZOICOV, D. Alfabetização científico-tecnológica para quê? Ensaio - Pesquisa em Educação em Ciências, v. 3, n. 2, p. 122-134, 2001.

BASTOS, A.P. S. Abordagem Temática Freireana e 0 ensino de ciências por investigação: contribuições para 0 ensino de ciências/física nos anos iniciais. 2013. 203 p. Dissertação (Mestrado em Educação Científica e Formação de Professores), Universidade Estadual do Sudoeste da Bahia, Jequié, 2013.

BIZZO, N. Ciências: fácil ou difícil? São Paulo: Biruta, 2009.

CARVALHO, A. M. P. ; GIL-PÉREZ, D. Formação de professores de ciências. São Paulo: Cortez, 2006. 
CENTA, F.G. "Arroio Cadena: cartão postal de Santa Maria?": possibilidades e desafios em uma reorientação curricular na perspectiva da abordagem temática. 2015. 203 p. Dissertação (Mestrado em Educação Matemática e Ensino de Física), Universidade Federal de Santa Maria, Santa Maria, 2015.

DELIZOICOV, D.; ANGOTTI, J. A.; PERNAMBUCO, M. M. C. A. Ensino de Ciências: Fundamentos e Métodos. São Paulo: Cortez, 2011.

DELIZOICOV, D. Conhecimento, Tensões e Transições. 1991. 2019 p. Tese (Doutorado em Educação), Faculdade de Educação da Universidade de São Paulo, São Paulo, 1991.

DELIZOICOV, D. Concepção problematizadora do ensino de ciências na educação formal. 1982. Dissertação (Mestrado em Educação) - Universidade de São Paulo, São Paulo, 1982.

FREIRE, P. Pedagogia do Oprimido. Rio de Janeiro: Paz e Terra, 2018.

FREIRE, P. A Sombra desta Mangueira, São Paulo: Olho d’Água, 2003.

GADOTTI, M. Paulo Freire: uma biobibliografia. São Paulo: Cortez, 1996. Glossário.

GATTI, B. A. A. Formaç̧ão de professores no Brasil: características e problemas. Educação e Sociedade, Campinas, v. 31, n. 113, p. 1355-1379, 2010.

GATTI, B.A.; BARRETO, E. S. S. Professores do Brasil: impasses e desafios. Brasília: Unesco, 2009.

HALMENSCHLAGER, K. R. Abordagem de temas em Ciências da Natureza no Ensino Médio: implicações na prática e na formação docente. 2014. 373 p. Tese (Doutorado em Educação Científica e Tecnológica), Universidade Federal de Santa Catarina, Florianópolis, 2014.

KLEIN, S.G.; MUENCHEN, C. Abordagem Temática como objeto de pesquisa: o que vem sendo investigado? Amazônia, v. 16, n. 36, p. 159-180, 2020. Doi: http://dx.doi.org/10.18542/amazrecm.v16i36.7446

KLEIN, S.G.; PEREIRA, D.N. ; MUENCHEN, C. Avaliação da aprendizagem na abordagem temática: um olhar para os três momentos pedagógicos. Investigações em Ensino de Ciências, v. 26, n. 1, p. 375-387, 2021. D0l: http://dx.doi.org/ 10.22600/1518-8795.ienci2021v26n1p375

LIBÂNEO, J. C. 0 ensino da didática, das metodologias especificas e dos conteúdos específicos do ensino fundamental nos currículos do curso de Pedagogia. Revista Brasileira de Estudos Pedagógicos, Brasília, v. 91, n. 229, p. 562-583, 2010.

LONGHINI, M. D. 0 conhecimento do conteúdo científico e a formação do professor das séries iniciais do ensino fundamental. Investigações em Ensino de Ciências, v. 13, n. 2, p. 241-253, 2008.

LORENZETTI, L.; DELIZOICOV, D. Alfabetização científica no contexto das séries iniciais. Ensaio Pesquisa em Educação em Ciências, v. 3, n. 1, p. 45-61, 2001.

MAESTRELLI, S.G. A abordagem CTSA nos anos iniciais do ensino fundamental: contribuições para o exercício da cidadania. 2018. 203 p. Dissertação (Mestrado em Educação em Ciências e em Matemática), Universidade Federal do Paraná, Curitiba, 2018. 
MAGOGA, T. F. Abordagem Temática na Educação em Ciências: um Olhar à luz da Epistemologia Fleckiana. 2017. 177 p. Dissertação (Mestrado em Educação em Ciências), Universidade Federal de Santa Maria, Santa Maria, 2017.

MAGOGA, T. F.; MUENCHEN, C. A Abordagem Temática Caracterizada por Pesquisadores da Área de Ensino de Ciências. Revista Brasileira de Pesquisa em Educação em Ciências, v. 20, p. 315-343, 2020. D0l: 10.28976/1984-2686rbpec2020u315343

MAGOGA, T. F., et al. Uma análise das práticas educativas baseadas na Abordagem Temática nas atas dos ENPECS. Anais do III Seminário Internacional de Educação em Ciências, Rio Grande, Rio Grande do Sul/Brasil, 2014.

MAGOGA, T.F.; SILVA, J.M.; MUENCHEN, C. Situação de Estudo e Abordagem Temática: Relações, Discussões e Sinalizações. Contexto \& Educação, ano. 35, n 111, p. 127-147, mai/ago. 2020. D0l: https://doi.org/10.21527/21791309.2020.111.127-147

MAIA, D. R. A.; MION, R.A. Curiosidade epistemológica e a formação do professor e pesquisador em ensino de física. In: VII Seminário de Pesquisa em Educação da Região Sul - ANPEDSul, Itajaí, Santa Catarina/Brasil, 2008.

MARQUES, S. G. Articulação Freire-CTS na formação de educadores dos anos iniciais. 2019. 131 p. Dissertação (Mestrado em Matemática e Ensino de Física), Universidade Federal de Santa Maria, Santa Maria, 2019.

MIZUKAMI, M. G. N. et al. Escola e aprendizagem da docência: processos de investigação e formação. São Carlos: EdUFSCar, 2002.

MORAES, R.; GALIAZZI, M.C. Análise textual discursiva. Ijuí: Editora Unijuí, 2011.

MUENCHEN, C. Configurações curriculares mediante o enfoque CTS: desafios a serem enfrentados na EJA. 2006. 129 p. Dissertação (Mestrado em Educação), Universidade Federal de Santa Maria, Santa Maria, 2006.

MUENCHEN, C. A disseminação dos três momentos pedagógicos: um estudo sobre práticas docentes na região de Santa Maria/RS. 2010. 273p. Tese (Doutorado em Educação Científica e Tecnológica), Universidade Federal de Santa Catarina, Florianópolis, 2010.

NERES, C.A.; GEHLEN, S.T. Investigação Temática na Formação de Professores: Indicativos da Pesquisa em Educação em Ciências. Revista Brasileira de Pesquisa em Educação em Ciências, v. 18, n. 1, p. 239-267, abr., 2018. D0l: 10.28976/1984-2686rbpec2018181239

NOVAIS, E.S.P. et al. 0 Processo de Redução Temática na Formação de Professores em Iguaí-BA. Alexandria, Florianópolis, v. 10, n. 1, p. 77-103, nov. 2017.

PEREIRA, D.N; KLEIN, S.G.; MUENCHEN, C. 0 papel da avaliação na Abordagem Temática: das características às implicações pedagógicas. Revista Eletrônica de Educação, 2021. No prelo.

RAMSEY, J. The science education reform movement: implications for social responsibility. Science Education, v. 77 , n. 2, p. 235-258, 1993.

SANTOS, W. L. P. ; MORTIMER, E. F. Uma análise de pressupostos teóricos da abordagem C-T-S (Ciência-Tecnologia-Sociedade) no contexto da educação brasileira. Ensaio: pesquisa em educação em ciências, v. 2, n. 2, p. 133-162, 2002. 
SAUL, A.M. Na contramão da lógica do controle em contextos de avaliação: por uma educação democrática e emancipatória. Educação e Pesquisa, v. 41, n. especial, p. 1299-1311, 2015. DOI: https://doi.org/10.1590/S1517-9702201508143035.

SAUL, A.M. Referenciais Freireanos para a prática da avaliação. Revista de Educação, n. 25, p. 17-24, 2008.

SILVA, A. F. G.; GOMES, C.G.S. Considerações sobre os fundamentos da proposta curricular freireana a partir da racionalidade crítica. In: Cap. 2 - Educação Científica Freireana na Escola. Org: Giselle Watanabe, São Paulo: Livraria da Física, 2019.

SILVA, A. F. G. A construção do currículo na perspectiva popular crítica: das falas significativas às práticas contextualizadas. (Tese de Doutorado) Programa de Estudos Pós-Graduados em Educação: Currículo da Pontifícia Universidade Católica de São Paulo, São Paulo, 2004.

SILVA, A. F. A. Ensino e aprendizagem de Ciências nas séries iniciais: concepções de um grupo de professoras em formação. (Dissertação de mestrado) Programa de Pós-Graduação em Ensino de Ciências da Universidade de São Paulo, São Paulo, 2006.

SOUZA, V. J. O., et al. 0 ensino de ciências nos anos iniciais: aprender e ensinar pela pesquisa. XI Encontro Nacional de Pesquisa em Educação em Ciências. Universidade Federal de Santa Catarina, Florianópolis, 2017.

VALADARES, J.; GRAÇA, M. Avaliando para melhorar a aprendizagem. Lisboa: Plátano Editora, 1998.

VIECHENESKI, J. P. ; LORENZETTI, L.; CARLETTO, M.R. Alfabetização Científica nos anos iniciais: uma análise dos trabalhos apresentados nos ENPECs. In: X Encontro Nacional de Pesquisa em Educação em Ciências, Águas de Lindóia, SP/Brasil, 2015.

VIECHENESKI, J.P. ; CARLETTO, M. R. Sequência didática para o ensino de ciências nos anos iniciais: subsídios para iniciação à alfabetização científica. Dynamis, Blumenau, v. 19, n. 1, p. 03-16, 2013.

VIECHENESKI, J. P. ; CARLETO, M. R. Ensino de Ciências e Alfabetização Científica nos anos iniciais do Ensino Fundamental: um olhar sobre as escolas públicas de Carambeí. In: VIII Encontro Nacional de Pesquisa em Educação em Ciências, Campinas, SP/Brasil, Anais..., Campinas., 2011.

RECEBIDO EM: 27 abr. 2021

CONCLUÍDO EM: 27 ago. 2021 
